\title{
SITUAÇÃO DA LEISHMANIOSE VISCERAL CANINA (LVC) NO ESTADO DE SÃO PAULO
}

\author{
Nássarah Jabur Lot Rodrigues ${ }^{1 *}$ \\ Rafaella Prestes Di Pietro Benetton ${ }^{2}$ \\ Natalie Neuwirt Oliveira ${ }^{2}$ \\ Suzane Manzini ${ }^{2}$ \\ Helio Langoni ${ }^{3}$
}

\begin{abstract}
RESUMO
A leishmaniose visceral (LV) é uma enfermidade zoonótica transmitida pelo flebotomíneo Lutzomyia longipalpis, conhecido popularmente como "mosquito-palha", tendo o cão doméstico como seu principal reservatório no ambiente urbano. Apresenta-se em plena expansão no estado de São Paulo, com 76 munícipios apresentando transmissão canina e humana, 54 municípios silenciosos receptivos vulneráveis no ano de 2015 , e com 13 casos humanos e dois óbitos registrados no primeiro trimestre do ano de 2019. O diagnóstico da Leishmaniose Visceral Canina (LVC) pode ser realizado através de técnicas indiretas ou diretas. O protocolo oficial do Ministério da Saúde preconiza a triagem pela técnica Dual Plath Platform (DPP) e a confirmação pela técnica de ensaio imunoenzimático (ELISA). O tratamento pode ser realizado com o medicamento Milteforan ${ }^{\mathrm{TM}}$ (miltefosina 2\%), o qual possibilita apenas a cura clínica do animal e redução da capacidade de transmissão. A eutanásia, por sua vez, permanece como medida de controle controversa, e a prevenção ainda figura como a melhor medida para controlar a transmissão da doença.
\end{abstract}

Palavras-chaves: Leishmaniose infantum, tratamento, epidemiologia, medidas preventivas.

\section{SITUATION OF CANINE VISCERAL LEISHMANIOSIS (LVC) IN THE STATE OF SÃO PAULO}

\begin{abstract}
Visceral leishmaniasis (VL) is a zoonotic disease transmitted by the phlebotomine vector Lutzomyia longipalpis, popularly known as "sandfly". In the urban environment, the main reservoir is the domestic dog. It is in full expansion throughout the São Paulo State, with 76 municipalities presenting canine and human transmission, 54 silent receptive vulnerable municipalities in 2015, and 13 human cases and two deaths recorded in the first quarter of 2019. The diagnosis of Canine Visceral Leishmaniasis (CVL) can be performed using indirect or direct techniques. The official protocol recommended by the Brazilian Ministry of Health uses the Dual Plath Platform (DPP) technique as screening test and the enzyme-linked immunosorbent assay (ELISA) as confirmatory test. Animal can be treated using Milteforan $^{\mathrm{TM}}$ (miltefosine 2\%), which allows only the clinical cure of the animal and the reduction of the transmission power. Euthanasia, in turn, remains as a controversial control measure. Prevention continues to be the best solution for the transmission of the disease.
\end{abstract}

Keywords: Leishmania infantum, treatment, epidemiology, preventive measures.

\footnotetext{
${ }^{1}$ FMB- UNESP- Botucatu. *Correspondência. nassarah_lot@yahoo.com.br

${ }^{2}$ FMVZ- Unesp- Botucatu

${ }^{3}$ Docente da FMVZ- Unesp- Botucatu, helio.langoni@unesp.br
}

Rodrigues NJL, Benetton RPDP, Oliveira NN, Manzini S, Langoni H. Situação da leishmaniose visceral canina (LVC) no estado de São Paulo. Vet. e Zootec. 2021; v28: 001-009. 


\section{SITUACIÓN DE LEISHMANIOSIS VISCERAL CANINA (LVC) EN EL ESTADO DE SÃO PAULO}

\section{RESUMEN}

La leishmaniasis visceral (LV) es una enfermedad zoonótica transmitida por el flebótomo Lutzomyia longipalpis, conocido popularmente como "mosquito de la paja". En el entorno urbano, el reservorio principal es el perro doméstico. Está en plena expansión en todo el estado de São Paulo, con 76 municipios con transmisión canina y humana, 54 municipios vulnerables receptivos silenciosos, en 2015, y 13 casos humanos y dos muertes registradas en el primer trimestre de 2019. El diagnóstico de leishmaniasis visceral canina (CVL) puede ser realizado utilizando técnicas indirectas o directas. El protocolo oficial utiliza la detección utilizando la técnica de Plataforma Dual Plath (DPP) y la confirmación mediante la técnica de ensayo inmunoenzimático (ELISA). El tratamiento puede ser realizado con el medicamento Millteforan $^{\mathrm{TM}}$, que permite solo la curación clínica del animal. La eutanasia, a su vez, sigue siendo una medida de control controvertida. La prevención sigue siendo la mejor solución para la transmisión de esta enfermedad.

Palabras claves: Leishmania infantum, tratamiento, epidemiología, medidas preventivas.

\section{INTRODUÇÃO}

A leishmaniose visceral (LV) é uma enfermidade zoonótica causada por um protozoário intracelular obrigatório de células do sistema fagocítico mononuclear (1). Pertence ao complexo Leishmania donovani (L. donovani), que compreende a L. donovani e Leishmania infantum (L. infantum). Nas Américas (Novo Mundo), o agente etiológico é a L. infantum, enquanto na Europa, Ásia e África, os agentes etiológicos são a L. infantum e a L. donovani (2).

A LV apresenta cerca de 300.000 novos casos anuais, sendo notificados de 20.000 a 40.000 por ano (3). Esta zoonose é uma das seis endemias prioritárias no mundo (4). É considerada de notificação compulsória e está presente em 62 países de forma endêmica (5), com $90 \%$ dos casos reportados oriundos de cinco países: Bangladesh, Índia, Nepal, Sudão e Brasil (6). No Brasil, a doença é causada pela L. infantum (7).

Ocorre através da picada de um vetor flebotomíneo (8), pertencente ao gênero Lutzomyia, sendo a espécie Lutzomyia longipalpis (Lu. longipalpis) a principal envolvida, e que possui atividade crepuscular e noturna. É conhecido popularmente como "mosquitopalha", "tatuquiras" e "birigui"; colonizando facilmente áreas próximas às casas, adaptandose a altas temperaturas e à baixa umidade (9). Sua reprodução ocorre em ambientes ricos em matéria orgânica e baixa luminosidade (1).

O cão doméstico é o principal reservatório na área urbana devido à maior proximidade com os seres humanos e à alta suscetibilidade à infecção (10-12). Esta parasitose pode acometer outras espécies de animais como roedores, marsupiais e edentados (4). Nos humanos, as manifestações clínicas da LV são febre alta, hepatoesplenomegalia, pancitopenia, hipergamaglobulinemia, perda de peso e anemia. Quando não tratada, evolui para óbito em mais de $90 \%$ dos casos. Os cães, quando infectados, podem permanecer assintomáticos por período indeterminado, o que dificulta o diagnóstico e favorece a transmissão da infecção. Os sinais clínicos geralmente são alterações cutâneas, como alopecia, eczema furfuráceo, úlceras e hiperqueratose, além de onicogrifose, emagrecimento, ceratoconjuntivite e paresia dos membros posteriores (13). 
No Brasil, a LV tinha um caráter eminentemente rural. Porém, atualmente, há uma adaptação gradativa a grandes e pequenos centros urbanos. No estado de São Paulo os relatos da doença em humanos e cães datam de 1999. No entanto, há registros de casos em muitas cidades do estado nos anos antes de 1998, em Araçatuba, Birigui e Bauru (14). Diante da expansão desta enfermidade, esta revisão tem como objetivo relatar os dados existentes sobre a situação atual no ano de 2019 da LVC no estado de São Paulo.

\section{REVISÃO BIBLIOGRÁFICA}

Na América Latina, a LV foi descrita em pelo menos 12 países. Em 90\% dos casos ocorre no Brasil, especialmente na região Nordeste (1). A Leishmaniose Visceral atinge as cinco regiões do país, com casos mais concentrados respectivamente nas regiões Nordeste, Norte, Sudeste, Centro-Oeste e Sul (2), a primeira com quase $50 \%$ dos casos do país (15). Em média, cerca de 3.500 casos são registrados anualmente, por volta dos anos 2000, com o coeficiente de incidência de 2,0 casos/100.000 habitantes no Brasil (15).

$\mathrm{Na}$ propagação do meio rural para o urbano, tornou-se uma das principais doenças que causam epidemias urbanas e com aumento de incidência e letalidade nos infectados $(2,16)$.O primeiro relato da doença em seres humanos no Brasil se deu em 1934, quando cortes histológicos de fígado de pacientes com suspeita de febre amarela foram corados por Penna e revelaram as formas amastigotas (17).

A leishmaniose visceral está registrada em 21 das 27 Unidades da Federação do Brasil e em aproximadamente 1.600 municípios ocorre transmissão autóctone (3). Entre os anos de 2005 e 2009 no Brasil, a média anual de casos foi de 3.679, com a taxa de letalidade de 5,8\% (4). A LVC está presente em 95 cidades do Estado de São Paulo, e a humana, em 66 áreas urbanas (3).

No estado de São Paulo, até o ano de 1998 não foram registrados casos humanos ou caninos autóctones da doença (18). O ano de 1998 foi o primeiro em que ocorreu um relato registrado em cães, em Araçatuba. Em 1999, foi a primeira cidade a confirmar um caso indígena da LV em humanos $(4,14,19)$. No ano seguinte foram registrados 17 casos humanos em Araçatuba e dois casos humanos no município de Birigui, mostrando a rápida expansão da doença (18). Araçatuba tem sido endêmica para LV humana, ainda que recentemente tenha diminuído o número de casos (4). A cidade de Bauru é uma das cidades mais afetadas do Estado, com 381 casos humanos confirmados entre 2004 e 2012 (3).

Em 2010 foram detectados pela primeira vez em Campinas casos de LVC por transmissão autóctone e, por isso, este município foi incluso no Programa de Controle e Vigilância de LVC. Esta parasitose foi notificada em 2011 e 2012 por meio de exames sorológicos e biologia molecular (20). Em 2014, um estudo, que foi realizado um inquérito sorológico, reportou 32,3\% de LVC em Ilha Solteira (20).

Em 2016 e 2017 foram registrados pela primeira vez casos de LV humanos autóctones nas cidades de Andradina, Araçatuba, Birigui, Mirandópolis, Valparaíso, Bauru, Penápolis, Adamantina, Marília, Tupã, Dracena, Junqueirópolis, Panorama, Presidente Epitácio e Votuporanga sucessivamente. Neste estudo, nota-se que a transmissão de LV entre 1999 até 2017 ocorreu em 15,03\% nos municípios paulistas, com o percentual médio de letalidade de $8,6 \%(21)$.

Em 2006, O Ministério da Saúde implementou o Programa de Vigilância e Controle da Leishmaniose Visceral (PVCLV) contendo medidas de diagnóstico e tratamento precoce em casos de LV, redução dos flebotomíneos, eliminação de reservatórios da doença e atividade de educação em saúde, com o objetivo de conter o avanço desta parasitose no Brasil e reduzir a morbidade de letalidade da mesma (16). Em 2015, segundo Boletim Epidemiológico Paulista (BEPA), 76 munícipios possuíam transmissão canina e humana e 54 municípios 
estavam classificados como silencioso receptivo vulnerável (1). Enquanto em 2019, segundo dados da Secretária de Saúde do Estado de São Paulo, foram registrados treze casos de leishmaniose visceral humana e dois óbitos no primeiro trimestre (16).

O agente etiológico é o protozoário Leishmania infantum (L. infantum), pertencente ao complexo Donovani, o qual apresenta duas formas distintas: uma flagelada ou promastigota, presente no tubo digestivo do vetor; e outra aflagelada ou amastigota, encontrada nos vertebrados. Nestes, apresenta-se como formas viscerais no baço, fígado, medula óssea e tecidos linfoides (22).

Ainda que o cão seja o principal hospedeiro na área urbana, a doença não é transmitida por lambidas, mordidas e contato direto com ele, mas sim pela picada de flebotomíneos do gênero Lutzomyia, sendo a espécie Lu. longipalpis a principal envolvida. Como já mencionado, o flebotomínio se reproduz em ambientes ricos em matéria orgânica e com baixa luminosidade (1). No meio silvestre, animais como lobos, coiotes e raposas atuam como reservatórios (14).

A enzootia canina tem precedido a ocorrência de casos humanos, pois a prevalência de casos em cães é maior que em humanos (2). Todos os cães infectados, mesmo sem sintomas aparentes, são fonte de infecção para o flebotomínio transmissor, e, portanto, um risco à saúde humana e de outros cães (3) .

A LVC caracteriza-se pela sua enorme variabilidade de manifestações clínicas, devido basicamente a fatores individuais relacionados exclusivamente ao tipo de resposta imunológica desenvolvida (resposta imune humoral e/ou celular), grau de infestação parasitária, tempo de evolução e órgãos afetados (23).

$\mathrm{O}$ animal pode desenvolver uma doença multissistêmica semelhante à doença em humanos. Baneth et al. (2008) relatam sinais clínicos comuns, como alterações de pele, linfoadenomegalia sistêmica, alterações nos olhos, palidez de mucosas, esplenomegalia, caquexia, epistaxe e onicogrifose (10). Os sinais clínicos podem demorar, em média, três a sete meses para aparecerem nesta espécie (1). Alguns dos cães infectados pelo protozoário não desenvolvem sintomatologia clínica (24).

O diagnóstico da LVC é extremamente importante para que a vigilância e o controle da disseminação de $L$. infantum sejam realizados. Não é estatisticamente possível que um método diagnóstico seja 100\% sensível e 100\% específico. Desta forma, o diagnóstico de LVC na população canina deve utilizar uma combinação de testes, sendo um teste para triagem e outro para a confirmação. Caso ambos resultem reagentes, considera-se o animal como positivo (2).

Os testes diagnósticos para LVC podem ser diretos e indiretos. Testes indiretos como reação de imunofluorescência indireta (RIFI), técnica de ensaio imunocromático (ELISA) e Teste rápido do Dual Plath Plataform (TR-DPP) procuram a presença de anticorpos contra o patógeno e não a presença do patógeno em si. Testes diretos como citopatológicos, histopatológicos, imunológicos e moleculares (Reação da Polimerase em Cadeia, PCR) procuram diretamente pela presença do parasita em células e tecidos. Testes indiretos tendem a ser mais sensíveis que os testes diretos e por isso são os mais utilizados em inquéritos populacionais (17). Porém, muitos cães podem resultar não reagentes a pesquisa a pesquisa de anticorpos, entretanto podem apresentar detecção positiva do antígeno. Assim, estes dados demonstram a diferença na sensibilidade e especificidade dos testes. Cada teste deve ser avaliado com critério.

Métodos sorológicos costumam a ser menos trabalhosos e invasivos, o que contribui para sua ampla utilização. Entretanto, são geralmente menos específicos que os métodos diretos, pois podem apresentar reações cruzadas $(25,26)$. Para um eficiente controle e vigilância da LVC, as unidades de vigilância de zoonoses devem considerar a relevância dos diagnósticos: clínico, epidemiológico e laboratorial (27). O xenodiagnóstico e a inoculação 
experimental em hamster são técnicas que podem ser utilizadas ocasionalmente, por ser um diagnóstico mais demorado que os demais (28). O Ministério da Saúde regulamenta a triagem pelo TR-DPP (Biomanguinhos-Fiocruz, Brasil) e, como confirmação, o ELISA para o diagnóstico oficial da doença nos animais (12).

O tratamento da LVC é controverso e complexo, visto que as drogas para leishmaniose geralmente têm um alto custo e são ineficientes. Ocorre somente uma cura dos sinais clínicos, com a possível redução da carga parasitária. É importante salientar que não ocorre a cura parasitológica na espécie canina. Acontece a diminuição do potencial de transmissão do cão infectado quando há o uso de miltefosina 3\%. A falha terapêutica tem importantes implicações epidemiológicas, porque os cães permanecem assintomáticos, tornando-os possíveis reservatórios para os flebotomíneos. Além disso, sucessivos ciclos ineficazes de tratamento levam ao risco de seleção de linhagens de parasitos resistentes às drogas, com risco ao ser humano (29).

Medicamentos humanos como anfotericida B, anfotericida lipossomal, antimoniato pentavalente e qualquer outro medicamento não registrado pelo Ministério da Agricultura, Pecuária e Abastecimento (MAPA), não podem ser utilizados para o tratamento da doença em animais domésticos, segundo a Portaria Interministerial ANVISA-MAPA, $\mathrm{n}^{\circ} 1.426$, de 11 de julho de 2008 (7).

Em 2016, o medicamento Milteforan ${ }^{\mathrm{TM}}$, produzido pela empresa Virbac, foi registrado no MAPA, autorizando o tratamento da LVC no país. Porém, a problemática da inexistência da cura parasitológica para a LVC permanece (31). A Nota Técnica conjunta, no 001/2016, os MAPA e MS autorizaram o registro do produto Milteforan ${ }^{\circledR}$, principal droga utilizada no tratamento da LVC na Europa e que não é utilizada no tratamento da doença humana no Brasil. No entanto, de acordo com o Conselho Federal de Medicina Veterinária (CFMV), não há nenhuma droga autorizada para o tratamento da LVC (32).

A vacina Leish-Tec ${ }^{\circledR}$, comercializada pela Ceva Saúde Animal, está disponível no mercado brasileiro. Segundo a Instrução Normativa $n^{\circ} 31$, de 09 de julho de 2007, deve ser utilizada como proteção individual para os cães e não como uma estratégia isolada de controle da doença em humanos, visto que não existem provas suficientes sobre a efetividade da vacina na redução de casos humanos da doença. Estudos demonstraram que animais vacinados que foram infectados apresentaram uma redução na transmissibilidade do parasito para o flebotomíneo, porém, mais estudos devem ser realizados para comprovar a efetividade da vacina em relação à transmissão humana da doença (31).

Diante deste cenário, a maioria dos cães com diagnósticos positivos no país ainda são submetidos à eutanásia, medida de controle recomendada pela Organização Mundial da Saúde (OMS). Contudo, a própria entidade reconhece que existem cães de grande valor afetivo, econômico e prático e, por isso, não podem ser indiscriminadamente eutanasiados (30). Além disso, existem estudos que contestam a eficácia desta medida, alegando que não existem provas suficientes de que o seu cumprimento implica na diminuição da transmissão da LV (33). Em 2016, o medicamento Milteforan ${ }^{\mathrm{TM}}$, produzido pela empresa Virbac ${ }^{\circledR}$, foi registrado no MAPA, autorizando o tratamento da LVC no país. Porém, a problemática da inexistência da cura parasitológica para a LVC permanece (32).

Diversos autores criticam a eficácia da eutanásia de cães soropositivos sobre a redução da incidência de casos humanos e caninos (33). Além disso, a literatura aponta evidências de que o tratamento dos cães poderia ser uma alternativa para o combate à doença, uma vez que cães tratados apresentam redução da carga parasitária e da infectividade para flebotomíneos (34). Entretanto, o tratamento de cães é objeto de discussão no Brasil, estando proibido pelos órgãos de saúde pública com o argumento de que o tratamento canino provoca resistência do parasito ao medicamento usado no tratamento humano e que, até o momento, não há um tratamento que bloqueie a transmissão do parasito do cão ao vetor (35).

Rodrigues NJL, Benetton RPDP, Oliveira NN, Manzini S, Langoni H. Situação da leishmaniose visceral canina (LVC) no estado de São Paulo. Vet. e Zootec. 2021; v28: 001-009. 


\section{CONSIDERAÇÕES FINAIS}

É evidente a rápida expansão da LVC no estado de São Paulo. Dados mostram a grande quantidade de cães infectados, o que demonstra a extrema importância da realização contínua de atividades de vigilância epidemiológica de forma a alertar e informar a população sobre os aspectos dessa importante enfermidade, contribuindo para um melhor controle e consequentemente, melhor prevenção da doença no estado e no país. Um dos grandes problemas é o alto custo do tratamento dos cães infectados, inviabilizando para muitos proprietários que não têm poder aquisitivo para manter o uso contínuo. Ainda sim, é importante o uso de coleiras contra o vetor/flebotomínio, vacinação e tratamento de cães que contribuem para minimização da transmissão desta doença em humanos. E o que poderia ajudar seria a população busque sempre manter os terrenos e quintais limpos para evitar a proliferação do flebotomínio (matéria orgânica).

\section{REFERÊNCIAS}

1 Brasil. Ministério da Saúde. Guia de vigilância epidemiológica [Internet]. 7a ed. Brasília: Ministério da Saúde; 2014 [citado 20 Jan 2020]. Disponível em: http://bvsms.saude.gov.br/bvs/publicacoes/guia_vigilancia_epidemiologica_7ed.pdf

2. Brasil. Ministério da Agricultura, Pecuária e Abastecimento e Ministério da Saúde. Registro do produto de uso veterinário denominado Milteforan 2\% Solução Oral para cães. Nota técnica conjunta $n^{\circ} 001 / 2016-$ MAPA/MS, de 17 de Agosto de 2016 [Internet]. Brasília: MAPA; 2016 [citado 20 Jan 2020]. Disponível em: https://www.sbmt.org.br/portal/wp-content/uploads/2016/09/nota-tecnica.pdf

3. Anversa L, Montanholi RJD, Sabino DL. Avaliação do conhecimento da população sobre leishmaniose visceral. Rev Inst Adolfo Lutz. 2016;75:1685.

4. Ortiz RC, Anversa L. Epidemiology of visceral leishmaniasis in Bauru, São Paulo, Brazil, 2004-2012: a descriptive study. Epidemiol Serv Saude. 2015;24(1):97-104. doi: 10.5123/S1679-49742015000100011.

5. Barbosa DS, Rocha AL, Santana AA, Souza CSF, Dias RA, Costa-Júnior LM, et al. Soroprevalência e variáveis epidemiológicas associadas à leishmaniose visceral canina em área endêmica no município de São Luís, Maranhão, Brasil. Cienc Anim Bras. 2010;11(3)635-59.

6. Pan American Health Organization. Leishmaniasis: 2007 [Internet]. Washington: PAHO 2007 [citado $16 \quad$ Out 2019]. http://www.paho.org/English/AD/DPC/CD/leish-2007.htm

7. Camargo-Neves VLF. A leishmaniose visceral americana no estado de São Paulo: situação atual. BEPA Bol Epidemiol Paul. 2007;4(48):12-4.

8. Cortes S, Vaz Y, Neves R, Maia C, Cardoso L, Campino L. Risk factors for canine leishmaniasis in an endemic Mediterranean region. Vet Parasitol. 2012;189(2-4):189-96. 
9. Marzochi KBF, Marzochi MCA, Silva VL, Carvalho RW, Souza MB, Gomes MZG, et al. Prospective evaluation of human visceral leishmaniasis after treatment in Rio de Janeiro, 1977-1993. In: Brandão Filho S, editor. Research and control of human leishmaniasis in Brazil. Recife: Fundação Oswaldo Cruz; 1993. p. 275-83.

10. Baneth G, Koutinas AF, Solano-Gallego L, Bourdeau P, Ferrer L. Canine leishmaniosis new concepts and insights on an expanding zoonosis: part one. Trends Parasitol. 2008;24(7):324-30.

11. Mendonca MGM, Brito FE, Rodrigues EHG, Bandeira V, Jardim ML, Abath FG. Persistence of Leishmania parasites in scars after clinical cure of American cutaneous leishmaniasis: is there a sterile cure? J Infect. 2004;189(6):1018-23.

12. Silva DA, Perlé CSFS, Mundes Junior AAV, Madeira MF, Figueiredo FB. Leishmaniose visceral canina em Cachoeiras de Macacu, Rio de Janeiro - relato de caso. Clin Vet. 2011;16(95):64-8.

13. Brodskyn CI, Kamhawi S. Biomarkers for Zoonotic Visceral Leishmaniasis in Latin America. Front Cell Infect Microbiol. 2018;8:245. doi: 10.3389/fcimb.2018.00245.

14. Schimming BC, Silva JRCP. Leishmaniose visceral canina: revisão de literatura. Rev Cientif Eletronica Med Vet. 2012;10(19):1-17.

15. Organização Panamericana da Saúde. Leishmanioses: informe epidemiológico nas Américas [Internet]. Washington: OPAS; 2016 [citado 15 Dez 2019]. Disponível em: www.paho.org/leishmaniosis

16. von Zuben APB, Donalísio MR. Dificuldades na execução das diretrizes do Programa de Vigilância e Controle da Leishmaniose Visceral em grandes municípios brasileiros. Cad Saude Publica. 2016;32(6):e00087415. doi: http://dx.doi.org/10.1590/0102$311 \mathrm{X} 00087415$.

17. Gontijo CMF, Melo MN. Leishmaniose visceral no Brasil: quadro atual, desafios e perspectivas. Rev Bras Epidemiol [Internet]. 2004 [citado 20 Ago 2019];7(3):338-49. Disponível

em: https://www.scielosp.org/scielo.php?pid=S1415790X2004000300011\&script $=$ sci_arttext $\underline{\text { thlng}}=\mathrm{es}$

18. Laranjeira DF. Avaliação da imunidade humoral e celular em cães naturalmente infectados com Leishmania (L.) chagasi e sua correlação com a transmissibilidade para o vetor [tese] [Internet]. São Paulo: USP; 2008 [citado 12 Set 2019]. Disponível em: https://www.teses.usp.br/teses/disponiveis/10/10133/tde27112008103013/publico/Daniela_Farias_Larangeira.pdf

19. Luvizotto MCR, Feitosa MM, Ikeda FA, Perri SHV. Aspectos clínicos de cães com leishmaniose visceral no município de Araçatuba - São Paulo (Brasil). Clin Vet. 2000;5(28):36-44. 
20. Zuben APB, Angerami RN, Castagna C, Baldini MBD, Donalisio MR. The first canine visceral leishmaniasis outbreak in Campinas, State of São Paulo Southeastern Brazil. Rev Soc Bras Med Trop. 2014;47(3):385-8. doi: http://dx.doi.org/10.1590/0037-8682-01262013 .

21. Rangel O. Reflexões sobre cenários, vigilância epidemiológica e controle da transmissão de leishmaniose visceral no estado de São Paulo. Rev Inst Adolfo Lutz. 2018;(77):e1754.

22. Alves GBB, Pinho FA, Silva SMMS, Cruz MSP, Costa FAL. Alteração cardíacas e pulmonares em cães sintomáticos e assintomáticos infectados naturalmente com Leishmania (leishmania) chagasi. Braz J Med Biol Res. 2010;43(3):310-5.

23. Nogueira FS, Lisboa JCVD. Zoonose avança no estado de São Paulo. Bol APAMVET. 2017;8(2):19-22.

24. Dantas-Torres F, Brito ME, Brandão-Filho SP. Seroepidemiological survey on canine leishmaniasis among dogs from an urban area of Brazil. Vet Parasitol. 2006;140(1-2):5460 .

25. Otranto D, Dantas-Torres F. Fleas and ticks as vectors of Leishmania spp. to dogs: caution is needed. Vet Parasitol. 2010;168(102):173-4.

26. Faria AR, Andrade HM. Diagnóstico da Leishmaniose Visceral Canina: grandes avanços tecnológicos e baixa aplicação prática. Rev Pan-Amazonica Saude. 2012;3(2):47-57.

27. Chagas RLA. Leishmaniose visceral canina: perfil epidemiológico do Distrito Federal, 2013 a 2017 [trabalho de conclusão de curso] [Internet]. Brasília: Universidade de Brasília; 2017 [citado 25 Set 2019]. Disponível em: https://bdm.unb.br/bitstream/10483/17981/1/2017_RebeccaLuniereChagas tcc.pdf

28. Ikeda-Garcia FA, Marcondes M. Métodos de diagnóstico da leishmaniose visceral canina. Clin Vet. 2007;12(71):34-42.

29. Moreno J, Nieto J, Chamizo C. The immune response and PBMC subsets in canine visceral leishmaniasis before and after chemotherapy. Vet Immunol Immunopathol. 1999;71(3/4):181-95.

30. World Health Organization. Global health observatory data - Leishmaniasis [Internet]. Geneva: WHO; 2014 [citado 18 Nov 2019]. Disponível em: http://www.who.int/gho/neglected_diseases/leishmaniasis/en/

31. Ministério da Agricultura, Pecuária e Abastecimento. 5o Encontro Nacional de Defesa Sanitária Animal - ENDESA. Biológico [Internet]. 2017 [citado 12 Set 2019];79(2):9-97. (Suplemento). Disponível em: http://www.biologico.sp.gov.br/uploads/docs/bio/suplementos/V79 2/86629e32-fc2c450f-8107-cd4e11054197.pdf

32. Conselho Federal de Medicina Veterinária. Brasília: CFMV; 2016 [citado 25 Out 2016]. Disponível em: http://portal.cfmv.gov.br/portal/noticia/index/id/4794/secao/6 
33. Costa PL. Comportamento da fauna de flebotomíneos com ênfase em Lutzomyia longipalpis, em área endêmica para leishmaniose visceral, município de Passira, agreste de Pernambuco [dissertação]. Recife: Centro de Pesquisas Aggeu Magalhães, Fundação Oswaldo Cruz; 2011.

34. Silva SM, Amorim IF, Ribeiro RR, Azevedo EG, Demicheli C, Melo MN, et al. Efficacy of combined therapy with liposome-encapsulated meglumine antimoniate and allopurinol in treatment of canine visceral leishmaniasis. Antimicrob Agents Chemother. 2012;56(6):2858-67.

35. Brasil. Secretaria de Vigilância em Saúde. Departamento de Vigilância Epidemiológica. Manual de vigilância e controle da leishmaniose visceral. Brasília: Ministério da Saúde; 2006.

Recebido em: 07/09/2020

Aceito em: 09/08/2021 